\title{
Eleições Municipais e a Pandemia da Covid-19: alternativas de ação e POSSÍVEIS IMPACTOS ${ }^{1,2}$
}

Acir Almeida ${ }^{3}$

\section{INTRODUÇÃO}

Em razão da pandemia da Covid-19, o Congresso Nacional promulgou, em 2 de julho de 2020, a Emenda Constitucional (EC) no 107, adiando as eleiçóes municipais dos dias 4 e 25 de outubro para 15 e 29 de novembro deste ano. Uma das alternativas trazidas ao debate público foi a transferência dos pleitos para 2022, de maneira que fossem realizados em conjunto com as próximas eleiçóes gerais. A proposta de unificação das eleiçóes municipais com as estaduais e federais teve o apoio da Confederação Nacional dos Municípios (CNM) e chegou a ser formalizada, por meio da Proposta de Emenda à Constituição no 19/2020, da autoria de vários senadores (Montalvão, 2020).

Este texto discute brevemente as três principais alternativas de ação a respeito das eleiçóes municipais em meio à pandemia, objeto do debate que culminou na $\mathrm{EC} \mathrm{no} \mathrm{107:} \mathrm{i)} \mathrm{manter} \mathrm{o} \mathrm{calendário} \mathrm{original} \mathrm{das}$ eleições; ii) adiá-las para 2022, unificando-as com os demais pleitos; ou iii) adiá-las por pouco tempo, realizando-as ainda neste ano. Conclui-se que a terceira alternativa, escolhida pelo Congresso, é a mais acertada, por ser a única que permite conciliar as necessárias precauçóes de saúde com as garantias democráticas. Além disso, ela está mais de acordo com o padrão de resposta da maioria dos países.

Esta discussão ancora-se em duas premissas. A primeira diz respeito ao fato de que, tal como em outras esferas da vida coletiva, o calendário e as atividades eleitorais devem se ajustar à evolução (esperada) da epidemia, para não colocar a saúde e a vida de pessoas em risco. A outra premissa é a de que os princípios democráticos impóem que se adotem medidas excepcionais, para que as restriçôes decorrentes da crise sanitária não afetem os resultados das eleiçóes.

\section{ALTERNATIVA 1: MANTER O CALENDÁRIO ORIGINAL DAS ELEIÇÕES}

A alternativa de manter o calendário original era a mais arriscada do ponto de vista sanitário, considerando-se as projeções sobre a evolução da pandemia. Segundo estudo do Ministério da Saúde, de março deste ano, o comportamento previsto da curva epidêmica era que seu platô, reversão inicial e queda acentuada ocorressem, respectivamente, em julho, agosto e setembro, coincidindo com atividades importantes do calendário eleitoral (Brito e Soares, 2020). No início de julho, projeçóes sobre a evolução de novos casos e óbitos no país (média móvel de catorze dias) mostravam tendência de crescimento até o final daquele mês (Covid-19 Analytics, 2020, p. 3).

Assim, segundo as informações disponíveis, o platô da pandemia coincidiria com as convençôes partidárias, originalmente marcadas para o período de 20 de julho a 5 de agosto. Nesses eventos, os

1. DOI: http://dx.doi.org/10.38116/bapi25art6

2. Esta é uma versão levemente modificada da Nota Técnica no 36, publicada pelo Ipea em abril de 2020. Como a publicação original é anterior às eleições, algumas informações foram aqui relacionadas como eventos futuros, ainda que já tivessem acontecido quando do processo de editoração desta nova versão. Optou-se, assim, por manter a forma original das frases, sem modificação do tempo verbal.

3. Técnico de planejamento e pesquisa na Diretoria de Estudos e Políticas do Estado, das Instituições e da Democracia (Diest) do Ipea. 
correligionários de cada partido se reúnem para debater e definir os candidatos e as coligaçóes com outras legendas. A princípio, as convençóes podem seguir um formato não presencial, de transmissão e participação on-line por meio das redes sociais. No entanto, existe risco considerável desse formato aumentar a influência dos líderes dos partidos, relativamente à dos correligionários, na definição dos candidatos e das alianças eleitorais.

Além disso, era muito provável que a epidemia ainda não estivesse controlada (como se confirmou posteriormente) durante boa parte do período de campanha, que se iniciaria em 16 de agosto. Embora os candidatos façam uso cada vez mais intenso da internet e das redes sociais, o contato direto com eleitores e apoiadores, aparentemente, ainda é parte importante das estratégias de campanha municipal, nas cidades pequenas e médias - ou seja, na maior parte do país (Sousa, 2019).

Por fim, a própria eleição estava marcada para data muito próxima do período previsto de reversão da curva epidêmica. Considerando-se que toda projeção tem um componente de incerteza e que o tempo da epidemia varia entre municípios, é muito provável que muitos deles ainda estejam sob severas restriçóes sanitárias no começo de outubro. Além do risco de agravar a epidemia, a realizaçáo do pleito nessas condições tenderia a aumentar substancialmente a abstenção eleitoral, especialmente da população de menor renda, para a qual são menos relevantes as sançóes (não monetárias) do não comparecimento.

Por esses motivos, era elevado o risco de o calendário original afetar negativamente tanto as eleiçôes como a saúde pública. ${ }^{4}$ No primeiro caso, por aumentar a influência dos caciques partidários na seleção dos candidatos e desestimular o comparecimento dos eleitores de menor renda. No segundo, em razão de a campanha eleitoral e a própria eleição ocorrerem durante a curva epidêmica.

\section{ALTERNATIVA 2: ADIAR AS ELEIÇÕES PARA 2022, UNIFICANDO-AS COM OS DEMAIS PLEITOS}

A CNM e alguns congressistas defenderam a transferência das eleições municipais para 2022, unificando-as com os pleitos estaduais e federais (Guedes, 2020; Weterman, 2020). Foi argumentado que, além de evitar os riscos associados à pandemia, a unificação reduziria o gasto público com eleições.

Essa alternativa era a menos plausível do ponto de vista jurídico. Isso porque ela consiste em uma ruptura do calendário eleitoral, o que, além de requerer mudanças legais e constitucionais, violaria a cláusula de anualidade (art. 16 da Constituição Federal), que veda alteraçôes normativas que afetem o processo eleitoral no período de um ano da data de sua entrada em vigor. O Supremo Tribunal Federal (STF) entende que essa cláusula é pétrea, conforme declarou ao vedar a aplicação da Lei da Ficha Limpa às eleiçóes de 2010 (Lei da Ficha Limpa..., 2011).

Também do ponto de vista democrático, a unificação das eleiçôes locais com as demais é muito questionável. No atual contexto, ela implicaria a prorrogação dos mandatos municipais, violando a delegação com base no voto popular da última eleição. Mesmo desconsiderando esse aspecto contextual, a unificação não encontra justificativa nem na literatura especializada nem na experiência internacional. Segundo os poucos estudos que avaliam os efeitos de eleiçóes unificadas em diferentes níveis de governo, embora essa fórmula aumente o comparecimento na eleição local (o que é de relevância questionável no caso brasileiro, pois o voto é obrigatório), ela estimula a nacionalização do debate, tirando de foco as questóes e os candidatos locais e, assim, dificultando a avaliação dos

4. 0 fechamento dos cartórios eleitorais durante a epidemia poderá prejudicar parcela pequena dos eleitores, mas não há razão para crer que isso possa produzir algum viés sobre os resultados eleitorais. 
mandatários desse nível de governo pelos eleitores (Bracco e Revelli, 2018; Benedictis-Kessner, 2018). Isso significa que a unificação traz o risco de reduzir a capacidade dos eleitores de recompensar e punir eficazmente os governantes municipais. Esse possível impacto (negativo) da unificação sobre a democracia local precisa ser levado em conta, além da eventual economia de recursos.

Os estudos descritivos sobre a experiência internacional mostram que o mais comum é a realização de eleições locais separadamente das nacionais. Por exemplo, segundo Anzia (2012), aproximadamente $80 \%$ das eleiçôes municipais norte-americanas ocorrem em datas diferentes das eleições nacionais. Fabre (2010), por sua vez, compilou informaçóes sobre as regras eleitorais e as eleiçôes do Canadá e de mais sete países europeus onde há eleiçôes subnacionais, e concluiu que, no período de 1945 a 2008, nenhum deles adotou regra impondo simultaneidade entre as eleiçóes subnacionais e a nacional, e que raramente as primeiras ocorreram juntamente com a segunda.

\section{ALTERNATIVA 3: ADIAR AS ELEIÇÕES POR POUCO TEMPO, REALIZANDO-AS AINDA EM 2020}

O adiamento das eleiçôes por pouco tempo (considerou-se até, no máximo, dezembro deste ano) permitirá sua realização com razoável segurança sanitária, haja vista a previsão do Ministério da Saúde de que, no período previsto, a maior parte do país estará na fase pós-platô da evolução da pandemia. Além disso, a realização das eleiçóes ainda este ano evitará que se prorroguem os mandatos dos atuais prefeitos e vereadores. Isso é desejável porque respeita a delegação com base no voto popular.

Em contrapartida, pode-se argumentar que as eleições produzirão descontinuidade nas políticas de enfrentamento da pandemia, devido à transição para os novos governos eleitos. Não é provável, contudo, que mesmo onde haja descontinuidade o impacto final seja negativo. Se pensarmos que os eleitores (re)elegem candidatos que defendem "boas" políticas, então mudanças de gestão são mais prováveis de ocorrer em municípios onde há políticas "ruins". Logo, mesmo levando em conta eventual descontinuidade, a eleiçáo tem o potencial de promover melhoras (do ponto de vista do eleitor) nas políticas de combate à pandemia.

A resposta da grande maioria dos países democráticos tem sido o adiamento de eleiçóes por poucos meses. Segundo as informações compiladas pela Fundação Internacional para Sistemas Eleitorais (International Foundation for Electoral Systems - IFES), até meados de agosto, 68 países haviam adiado um total de 103 eleiçóes ou referendos (IFES, 2020). Para 36 desses casos, a nova data ainda não havia sido definida. Entre os outros 67, o tempo médio de adiamento foi de 3,5 meses, sendo que, em metade dos casos, ele não passou de 2,5 meses. Entre as democracias consolidadas, os únicos casos de adiamento por tempo muito longo ocorreram na Alemanha (oito meses), na Austrália (um ano), no Canadá (um ano) e na Inglaterra (um ano). Muito provavelmente, a extensão do adiamento depende da gravidade da crise e da fase (esperada) da curva epidêmica na data da eleição.

\section{CONCLUSÃO}

A evolução prevista da pandemia da Covid-19 no Brasil impôs o adiamento das eleiçóes municipais deste ano. Considerando a alternativa de transferi-las para 2022, estendendo-se os atuais mandatos de prefeitos e vereadores, o adiamento para novembro foi a decisão mais acertada porque, além de estar de acordo com as recomendaçóes de segurança sanitária, preserva princípios democráticos, como o mandato popular e a estabilidade das regras de competição política. Além disso, a decisão segue o padrão de ajuste dos calendários eleitorais da maioria dos países. 


\section{REFERÊNCIAS}

ANZIA, S. F. Partisan power play: the origins of local election timing as an American political institution. Studies in American Political Development, v. 26, n. 1, p. 24-49, 2012.

BENEDICTIS-KESSNER, J. de. Off-cycle and out of office: election timing and the incumbency advantage. The Journal of Politics, v. 80, n. 1, p. 119-132, 2018.

BRACCO, E.; REVELLI, F. Concurrent elections and political accountability: evidence from Italian local elections. Journal of Economic Behavior and Organization, v. 148, p. 135-149, 2018.

BRITO, F.; SOARES, I. Ministro da Saúde anuncia previsão de colapso do sistema no fim de abril. Correio Braziliense, 20 mar. 2020. Disponível em: <www.correiobraziliense.com.br/app/noticia/ politica/2020/03/20/interna_politica,835626/ministro-da-saude-anuncia-previsao-de-colapso-dosistema-no-fim-de-abr.shtml>.

COVID-19 ANALYTICS. Brasil: a situação em 9 de julho de 2020. [s.l.]: [s.n.], 10 jul. 2020. Disponível em: <https://covid19analytics.com.br/wp-content/uploads/2020/07/20200711Relat\%C3\%B3rio-covid19analytics.pdf>.

FABRE, E. Multi-level election timing: a comparative overview. Regional and Federal Studies, v. 20, n. 2, p. 175-199, 2010.

GUEDES, A. Propostas para adiar eleiçôes ganham força entre senadores. Agência Senado, 30 mar. 2020. Disponível em: <www12.senado.leg.br/noticias/materias/2020/03/30/propostas-para-adiareleicoes-ganham-forca-entre-senadores>.

IFES - INTERNATIONAL FOUNDATION FOR ELECTORAL SYSTEMS. Elections postponed due to Covid-19. [s.1.]: IFES, 2020. Disponível em: <www.ifes.org/sites/default/files/ elections_postponed_due_to_covid-19.pdf>.

LEI DA FICHA LIMPA não deve ser aplicada às eleiçôes 2010. Notícias STF, 23 mar. 2011. Disponível em: <www.stf.jus.br/portal/cms/verNoticiaDetalhe.asp?idConteudo=175082>.

MONTALVÃO, R. Unânimes, líderes municipalistas confirmam inviabilidade das eleições 2020. Agência CNM de Notícias, 25 maio 2020. Disponível em: <www.cnm.org.br/comunicacao/noticias/ unanimes-lideres-municipalista-confirmam-inviabilidade-das-eleicoes-2020>.

NO TSE, Barroso fala em adiamento "mínimo" das eleições. Correio Braziliense, 17 abr. 2020. Disponível em: <www.correiobraziliense.com.br/app/noticia/politica/2020/04/17/interna_ politica,845524/no-tse-barroso-fala-em-adiamento-minimo-das-eleicoes.shtml>.

SOUSA, D. S. Campanhas tradicionais ou modernas? As estratégias políticas nas eleiçóes municipais de 2016. 2019. Dissertação (Mestrado em Ciência Política) - Universidade Federal de Pernambuco, Recife, 2019.

WETERMAN, D. "Suspender as eleições é inevitável”, diz presidente da Confederação dos Municípios. O Estado de S. Paulo, 23 mar. 2020. Disponível em: <https://politica.estadao. com.br/noticias/eleicoes,suspender-as-eleicoes-e-inevitavel-diz-presidente-da-confederacao-dosmunicipios,70003244792>. 